\title{
HTEA Tabanlı KEMIRA-M Yöntemi ile Sağlık Sektöründe Risk Değerlendirme
}

\author{
Nuray Arslan ${ }^{1}$, Elif Kılıç Delice $2^{*}$ \\ ${ }^{1}$ Atatürk Üniversitesi,Mühendislik Fakültesi, Endüstri Mühendisliği Bölümü, Erzurum, Türkiye (ORCID ID 0000-0003-4605-6782), nryarsln.25@gmail.com \\ ${ }^{2}$ Atatürk Üniversitesi,Mühendislik Fakültesi, Endüstri Mühendisliği Bölümü, Erzurum, Türkiye(ORCID ID 0000-0002-3051-0496), elif.kdelice@atauni.edu.tr
}

(1st International Conference on Applied Engineering and Natural Sciences ICAENS 2021, November 1-3, 2021)

(DOI: 10.31590/ejosat.1011721)

ATIF/REFERENCE: Arslan, N., Delice, E.K. (2021). HTEA Tabanlı KEMIRA-M Yöntemi ile Sağlık Sektöründe Risk Değerlendirme. Avrupa Bilim ve Teknoloji Dergisi, (28), 853- 862.

\section{$\ddot{O} \mathbf{z}$}

Acil servislerde iş sağlığı ve güvenliği ile ilgili risklerin belirlenmesi ve bu risklere karşı gerekli önlemlerin alınması; sağlık çalışanlarının iş yüklerinin azaltılması ve sağlık hizmetlerinin kalitesinin arttırılması için son derece önemlidir. Bu nedenle uygun risk değerlendirme yöntemleri kullanılarak risk kriterleri (faktörleri) ve bu kriterleri azaltmak için alınacak risk önlemleri belirlenmelidir. $\mathrm{Bu}$ çalışmada; acil servislerde risk değerlendirilmesi için Hata Türleri ve Etkileri Analizi (HTEA) tabanlı Kemeny Median Indicator Ranks Accordance-Modified (KEMIRA-M) yöntemi önerilmiştir. İlk aşamada; HTEA yöntemi kullanılarak uzman görüşlerine göre risk kriterlerinin öncelikleri bulunmuştur. İkinci aşamada ise; KEMIRA-M yöntemi ile elde edilen medyan matrisine göre kriter öncelikleri belirlenmiş ve bu önceliklere göre risk kriterlerini azaltıcı önlemler açıklanmıştır. KEMIRA-M yöntemi hem HTEA yöntemi ile geliştirilmiş hem de ana ve alt kriterlerden oluşan hiyerarşik bir yapıdaki kriter grubuna uygulanmıştır. Önerilen yöntem ile acil servislerde yapılan risk değerlendirmesi sonucunda güvensiz nöbet-vardiya ortamı, tıbbi cihazlar ve ergonomi ile ilgili riskler en önemli risk kriterleri olarak belirlenmiştir. Bu risklerin azaltılması için çalışma koşullarının ergonomik açıdan düzenlenmesi, kişisel koruyucu donanımların kullanımı ve işçilere eğitim/seminer verilmesi önerilmiştir.

\section{Risk Assessment in the Health Sector with the FMEA-Based KEMIRA-M Method}

\begin{abstract}
Identifying risks related to occupational health and safety in emergency services and taking necessary precautions against these risks; It is extremely important for reducing the workload of health workers and increasing the quality of health services. For this reason, risk criteria (factors) and risk measures to be taken to reduce these criteria should be determined by using appropriate risk assessment methods. In this study; Failure Types and Effects Analysis (FMEA) based Kemeny Median Indicator Ranks Accordance-Modified (KEMIRA-M) method has been proposed for risk assessment in emergency services. First stage; By using the FMEA method, the priorities of the risk criteria were found according to expert opinions. In the second stage; Criteria priorities were determined according to the median matrix obtained by the KEMIRA-M method and measures to reduce risk criteria were explained according to these priorities. The KEMIRA-M method was developed with the FMEA method and was applied to a hierarchical criteria group consisting of main and sub-criteria. As a result of the risk assessment made in the emergency services with the proposed method, the most important risk criteria were determined as the unsafe duty-shift environment, risks related to medical devices and ergonomics. In order to reduce these risks, it has been suggested that the working conditions should be arranged ergonomically, the use of personal protective equipment and training/seminar should be given to the workers.
\end{abstract}

Keywords: Emergency Service, Risk Assessment, Multi-Criteria Decision Making, FMEA, KEMIRA-M

\section{Giriş}

Hastanelerin en önemli birimlerinden birisi olan acil servisler, acilen bakılması gereken hastaların ilk müdahalelerinin

\footnotetext{
* Sorumlu Yazar: elif.kdelice@atauni.edu.tr
} 
ve tedavilerinin yapıldığı bölümler olarak bilinmektedir. Acil servislerde çalışan personel her gün birçok riskle karşı karşıya kalmaktadır. Karşılaşılan risklerin belirlenmesi ve bu risklere karşı gerekli önlemlerin alınması; sağlık çalışanlarının çalışma koşullarının iyileştirilmesi ve sağlık hizmetlerinin kalitesini arttırmak açısından son derece gereklidir. $\mathrm{Bu}$ nedenle acil servislerde yapılan risk değerlendirme çalışmaları gün geçtikçe artmaktadır.

Risk değerlendirme sürecinde kullanılacak olan en uygun yöntemin belirlenmesi risklerin ve bu risklere karşı alınabilecek önlemlerin doğru belirlenmesi için önemli bir aşamadır. Bu süreç birden fazla ve çelişen kriteri kapsaması nedeniyle karar verici (KV)' ler için zor ve karmaşık bir süreçtir. ÇKKV yöntemleri birden fazla alternatifin alanında uzman KV'lerin görüşleri dikkate alınarak birbiriyle çelişen birden fazla kritere göre değerlendirilmesiyle alternatiflerin seçilmesi/sıralanmasını sağlayan bir karar yaklaşımıdır. Risk değerlendirme sürecinde Çok Kriterli Karar Verme (ÇKKV) yöntemlerinin kullanılması daha kapsamlı ve doğru sonuçların elde edilmesini sağlamaktadır.

Bu çalışmada ÇKKV yöntemlerinden biri olan ve Krylovas $v d$. [15] tarafindan önerilen Kemeny Median Indicator Ranks Accordance-Modified (KEMIRA-M) yöntemi risk değerlendirmesi için Hata Türleri ve Etkileri Analizi (HTEA) ile geliştirilmiş ve yeni bir risk değerlendirme yöntemi olarak HTEA tabanlı KEMIRA-M yöntemi önerilmiştir. HTEA uygulaması; potansiyel hataları tanımlamakta ve her hatanın nedenlerini ve etkilerini belirlemektedir HTEA hatalar ortaya çıkmadan hatanın tespit edilip gerekli önlemlerin alınması, hatanın etkisinin en alt düzeye indirilmesi, mümkün olduğu sürece hatanın tamamen ortadan kaldırılmasını amaçlayan bir risk değerlendirme yöntemidir. KEMIRA-M yöntemi ise kriterlerin kendi içinde birkaç kriter grubuna ayrıldığı durumlarda kriter ağırlıklarının belirlenmesi ve bu ağırlıkların kullanılarak alternatif seçimi yapılmasını sağlayan bir yöntemdir. KEMIRA-M yöntemi diğer ÇKKV yöntemlerine kıyasla çok daha az başlangıç bilgisi gerektirir. Yöntem, uzmanlardan bilgi toplamanın oldukça zor olduğu durumlarda kullanılır [3]. Sadece birkaç uzman tarafından belirlenen kriter sıralamaları ile bu yöntemin uygulanması için yeterlidir [15].

Önerilen HTEA tabanlı KEMIRA-M yönteminde kriter öncelikleri HTEA yöntemi ile elde edilen Risk Öncelik Sayısı (RÖS)'na göre belirlenmiştir. Daha sonra bu öncelikler KEMIRA-M yönteminde medyan matrisinin hesaplanmasında kullanılmış ve böylece risk kriterlerinin ağırlıkları bulunmuştur. KEMIRA-M yönteminde KV'ler kendi tecrübelerine dayanarak kriter önceliklerini belirlemektedirler. $\mathrm{Bu}$ çalışmada HTEA yöntemi kullanılarak KEMIRA-M yönteminde uzman değerlendirmelerinden kaynaklanan sübjektiflik azaltılmış ve kriter önceliklerinin daha doğru bir şekilde belirlenmesi sağlanmıştır. Geliştirilen HTEA tabanlı KEMIRA-M yöntemi ile acil servislerde sağlık personeli için risk değerlendirilmesi yapılarak en önemli risk kriterleri belirlenmiştir.

HTEA yöntemi literatürde sağlık alanında; risk yönetimi modeli oluşturmak, iş ve meslek hastalıkları yönünden risk durumunu incelemek, sağlık çalışanlarında psikososyal risk faktörlerini belirlemek, acil servislerinin risk seviyelerini sıralamak, elektronik reçete için güvenlik modeli geliştirmek, acil servislerdeki iletişim sürecini iyileştirmek, HTEA yürütülürken karşılaşılan sorunların üstesinden gelmek, HTEA yönteminin sağlık hizmetlerinde stratejik bir yeri olan hasta güvenliğine katkısını incelemek, hasta - hekim ilişkisindeki eksikliklerin ve hataların, hasta açısından varsayımsal etkilerini incelemek, ambulansların hasta getirme alanını haritalamak ve hasta güvenliğini veya işlem verimliliğini tehlikeye atabilecek adımları belirlemek için tehlike analizi yapmak ve acil servis departmanını iyileştirmek için kullanılmıştır. ([1],[10],[12],[9],[11],[22],[27],[2],[6],[7],[26])

KEMIRA-M yöntemi literatürde; atık geri dönüşüm tesisi yer seçimi, güvenlik personeli seçimi, oylama teorisi ile ilk defa karşılaştırma yapılması, insan kaynakları seçimi, forklift seçimi, şantiyelerde risk değerlendirmesi, mermer kesme makinesinin seçimi, alışveriş merkezi seçimi, drone seçimi, depo yeri seçimi, alternatif altı sigma projelerinin önceliklendirilmesi ve seçimi, acil servislerde ve boru imalatında ergonomik risk değerlendirmesi için kullanılmıştır ([15],[3],[14],[17],[16],[23],[30],[24],[29],[13],[20],[4],[8]).

Bu çalışma çeşitli yönlerden literatüre katkı sağlamaktadır. İlk defa HTEA ve KEMIRA-M yöntemi birlikte kullanılmıştır. KEMIRA-M hiyerarşik bir kriter yapısına uygulanmıştır. Literatürde hiyerarşik yapıyı uygulayan bir çalışma bulunmamaktadır [4]. Ayrıca, bu çalışmada literatürde az sayıda çalışmanın olduğu acil servislerde risk değerlendirme konusu ele alınmış ve ÇKKV yöntemleri kullanılarak daha kapsamlı bir risk değerlendirmesi yapılmıştır.

Çalışmanın ikinci kısmında, HTEA ve KEMIRA-M yöntemleri hakkında bilgi verilecek ve önerilen yöntem açıklanacaktır. Üçüncü bölümde, önerilen yöntem kullanılarak acil servisler bölümünde gerçekleştirilen risk uygulamasından bahsedilecektir. Son bölümde sonuç ve tartışma verilektir.

\section{Materyal ve Metot}

\subsection{HTEA Yöntemi}

HTEA yöntemi; olasılık, şiddet ve saptanabilirliğe bağlı olarak hataların önceliğini ortaya çıkarmaktadır. Sorunların izlenmesini ve düzeltici faaliyetlerin yapılmasını sağlamaktadır [19].

Olasılık(O): Her bir hata türünün meydana gelme olasılığı olarak tanımlanmaktadır. HTEA olasılık değerlendirme skalası Tablo 1 'de gösterilmiştir [25].

Şiddet(Ş): Hatanın sebep olabileceği zararın değeri olarak tanımlanmaktadır. HTEA şiddet değerlendirme skalası Tablo 2'de gösterilmiştir [19].

Saptanabilirlik (S): Hataların önceden belirlenebilmesinin zorluk derecelendirilmesi olarak tanımlanmaktadır. Saptanabilirlik değerlendirme skalası Tablo 3'de gösterilmiştir [19].

Risk Öncelik Sayısı (RÖS): Olasılık, şiddet ve saptanabilirlik değerlerine bağlı olarak Eşitlik (1) kullanılarak elde edilen değerdir. Risklerin öncelik sıraları RÖS değeri ile belirlenir.

$$
\mathrm{RÖS}=\mathrm{O} * \mathrm{~S}^{*} \mathrm{~S}
$$


Tablo 1. Olasılık Skalası

\begin{tabular}{|c|c|c|}
\hline Hata olasılığı & Hatanın ihtimali & Derece \\
\hline Oldukça yüksek & 1/ 2 den fazla & 10 \\
\hline Çok yüksek & $1 / 3$ & 9 \\
\hline . & . & \\
\hline Çok düşük & $1 / 150000$ & 2 \\
\hline $\begin{array}{l}\text { Hemen hemen } \\
\text { olanaksiz }\end{array}$ & $\begin{array}{l}\text { 1/1500000 den } \\
\text { fazla }\end{array}$ & 1 \\
\hline
\end{tabular}

Tablo 2. Şiddet Skalası

\begin{tabular}{|c|c|c|}
\hline Etki & Şiddetin etkisi & Derece \\
\hline $\begin{array}{c}\text { Uyarısız gelen } \\
\text { tehlike }\end{array}$ & $\begin{array}{c}\text { Felakete yol açabilecek } \\
\text { ve uyarısız gelen } \\
\text { potansiyel hata }\end{array}$ & 10 \\
\hline $\begin{array}{c}\text { Uyarısız gelen } \\
\text { tehlike }\end{array}$ & $\begin{array}{c}\text { Yüksek hasara ve toplu } \\
\text { ölümlere yol açabilecek } \\
\text { etkiye sahip ve uyarısız } \\
\text { gelen potansiyel hata }\end{array}$ & 9 \\
\hline$\cdot$ & $\cdot$ & $\cdot$ \\
$\cdot$ & $\cdot$ & $\cdot$ \\
\hline Çok küçük & $\begin{array}{c}\text { Sistemin çalışmasında } \\
\text { kargaşaya yol açan hata }\end{array}$ & 2 \\
\hline Yok & Etki yok & 1 \\
\hline
\end{tabular}

Tablo 3. Saptanabilirlik Skalası

\begin{tabular}{|c|c|c|}
\hline Saptanabilirlik & Saptanabilirlik olasılığı & Derece \\
\hline Fark edilemez & $\begin{array}{c}\text { Potansiyel hatanın } \\
\text { nedeninin ve takip eden } \\
\text { hatanın keşfedilebilirliği } \\
\text { mümkün değil }\end{array}$ & 10 \\
\hline Çok az & $\begin{array}{c}\text { Potansiyel hatanın } \\
\text { nedeninin ve takip eden } \\
\text { hatanın keşfedilebilirliği } \\
\text { çok uzak }\end{array}$ & 9 \\
\hline$\cdot$ & $\cdot \quad$ & $\cdot$ \\
\hline Çok Yüksek & $\begin{array}{c}\text { Potansiyel hatanın } \\
\text { nedeninin ve takip eden } \\
\text { hatanın keşfedilebilirliği } \\
\text { çok yüksek }\end{array}$ & 2 \\
\hline $\begin{array}{c}\text { Hemen Hemen } \\
\text { Kesin }\end{array}$ & $\begin{array}{c}\text { Potansiyel hatanın } \\
\text { nedeninin ve takip eden } \\
\text { hatanın keşfedilebilirliği } \\
\text { hemen hemen kesin }\end{array}$ & \\
\hline
\end{tabular}

\subsection{KEMIRA-M Yöntemi}

KEMIRA-M yöntemiyle problem çözümünün ilk aşamasında, KV değerlendirmeleri ile kriterlerin önceliği Kemeny Medyan (Kemeny Median) yöntemi kullanılarak belirlenirken; ikinci aşamada, kriter ağırlıkları Sıralama Uygunluk Göstergesi (Indicator Rank Accordance) yöntemi kullanılarak belirlenmektedir. KEMIRA-M yönteminin adımları aşağıda verilmiştir ([14], [13]).

\section{Adım 1: KV' lerin ve kriterlerin belirlenmesi}

İlk olarak araştırılacak konuda uzman kişilerden oluşan bir $\mathrm{KV}$ grubu oluşturulur ve $K V_{s} ; s=1, \ldots S$ ile ifade edilir. Daha sonra $x_{j} ; j=1, \ldots, m$, ve $y_{j} ; j^{\prime}=1, \ldots, n$; olmak üzere; KV' ler tarafından iç ve dış kriterler belirlenir. Son olarak, kriter grubuna bağlı olarak alternatifler belirlenir ve $R_{\mathrm{i}} ; i=1, \ldots K$ ile ifade edilir.

\section{Adım 2: Bașlangıç karar matrisinin olușturulması}

Her bir KV için ana iç ve ana diş kriter gruplarına ait başlangıç karar matrisleri $\left[D_{X} \vdots D_{Y}\right]$, Eşitlik (2)' de gösterildiği gibi oluşturulur.

$$
\left[\mathrm{D}_{\mathrm{X}} \vdots \mathrm{D}_{\mathrm{Y}}\right]=\left[\begin{array}{ccccccccccc}
\mathrm{y}_{1}^{(1)} & \ldots & \mathrm{y}_{\mathrm{j}^{\prime}}^{(1)} & \ldots & \mathrm{y}_{\mathrm{n}}^{(1)} & \vdots & \mathrm{x}_{1}^{(1)} & \ldots & \mathrm{x}_{\mathrm{j}}^{(1)} & \ldots & \mathrm{x}_{\mathrm{m}}^{(1)} \\
\ldots & \ldots & \ldots & \ldots & \ldots & \vdots & \ldots & \ldots & \ldots & \ldots & \ldots \\
\mathrm{y}_{1}^{(\mathrm{i})} & \ldots & \mathrm{y}_{\mathrm{j}^{\prime}} & \ldots & \mathrm{y}_{\mathrm{n}}^{(\mathrm{i})} & \vdots & \mathrm{x}_{1}^{(\mathrm{i})} & \ldots & \mathrm{x}_{\mathrm{j}}^{(\mathrm{i})} & \ldots & \mathrm{x}_{\mathrm{m}} \\
\ldots & \ldots & \ldots & \ldots & \ldots & \vdots & \ldots & \ldots & \ldots & \ldots & \ldots \\
\mathrm{y}_{1}^{(\mathrm{K})} & \ldots & \mathrm{y}_{\mathrm{j}^{\prime}}^{(\mathrm{K})} & \ldots & \mathrm{y}_{\mathrm{n}}^{(\mathrm{K})} & \vdots & \mathrm{x}_{1}^{(\mathrm{K})} & \ldots & \mathrm{x}_{\mathrm{j}}^{(\mathrm{K})} & \ldots & \mathrm{x}_{\mathrm{m}}^{(\mathrm{K})}
\end{array}\right]
$$

Burada; $\mathrm{x}_{\mathrm{j}}^{(\mathrm{i})} i$. alternatifin $\mathrm{j} .(\mathrm{j}=1, \ldots, \mathrm{m})$ ana iç kriter için aldığ 1 değeri ve $\mathrm{y}_{\mathrm{j}^{\prime}}^{(\mathrm{i})} i$. alternatifin $\mathrm{j}^{\prime}\left(\mathrm{j}^{\prime}=1, \ldots, \mathrm{n}\right)$ ana dış kriter için aldığ değeri göstermektedir.

\section{Adım 3: Başlangıç karar matrisinin normalize edilmesi}

Oluşturulan başlangıç karar matrisi normalize edilmektedir. Eşitlik (3)'de ana kriterler için gösterilmiştir [32]. Aynı işlemler alt kriterler için de geçerlidir.

$\mathrm{x}_{\mathrm{j}}^{(\mathrm{i}) *}=\left(\mathrm{x}_{\mathrm{j}}^{(\mathrm{i})}\right) / \sqrt{\sum_{j=1}^{m} \mathrm{x}_{\mathrm{j}}^{(\mathrm{i})^{2}}}$,

$\mathrm{y}_{\mathrm{j}^{\prime}}^{(\mathrm{i}) *}=\left(\mathrm{y}_{\mathrm{j}^{\prime}}^{(\mathrm{i})}\right) /{\sqrt{\sum_{j^{\prime}=1}^{n} \mathrm{y}_{\mathrm{j}^{\prime}}^{(\mathrm{i})^{2}}}}^{\mathrm{i}}=1,2, \ldots \mathrm{K}$

Burada, $\mathrm{x}_{\mathrm{j}}^{(\mathrm{i})^{*}} i$. alternatifin $\mathrm{j}$. iç kriter için normalize edilmiş değerini ve $\mathrm{y}_{\mathrm{j} \prime}^{(\mathrm{i})^{*}} i$. alternatifin $\mathrm{j}^{\prime}$. dış kriter için normalize edilmiş değerini göstermektedir.

\section{Adım 4: Her bir KV için kriter önceliklerinin belirlenmesi}

KV' ler, birbirlerinden bağımsız bir şekilde her iki kriter grubu için ayrı ayrı kriter önceliklerini belirlerler. Kriter önceliği olarak " 1 " değerini alan kriterin, diğerlerinden daha önemli olduğu düşünülmektedir. $\mathrm{KV}$ ' ler tarafından belirlenen kriter öncelikleri Tablo 4'de ana kriterler için gösterilmiştir. Benzer işlemler alt kriterler için de geçerlidir.

Tablo 4. Kriterler İçin KV'ler Tarafindan Belirlenen Öncelikler

\begin{tabular}{|c|c|c|c|c|c|c|c|c|c|c|}
\hline $\boldsymbol{D} \boldsymbol{M}_{\boldsymbol{s}}$ & $\boldsymbol{y}_{\mathbf{1}}$ & $\cdots$ & $\boldsymbol{y}_{\boldsymbol{j}^{\prime}}$ & $\cdots$ & $\boldsymbol{y}_{\boldsymbol{J}^{\prime}}$ & $\boldsymbol{x}_{\mathbf{1}}$ & $\cdots$ & $\boldsymbol{x}_{\boldsymbol{j}}$ & $\cdots$ & $\boldsymbol{x}_{\boldsymbol{J}}$ \\
\hline 1 & $\left(y_{1}\right)_{r}^{1}$ & $\cdots$ & $\left(y_{j^{\prime}}\right)_{\eta}^{1}$ & $\cdots$ & $\left(y_{J^{\prime}}\right)_{r}^{1}$ & $\left(x_{1}\right)_{r}^{1}$ & $\cdots$ & $\left(x_{j}\right)_{r}^{1}$ & $\cdots$ & $\left(x_{J}\right)_{r}^{1}$ \\
\hline$S$ & $\left(y_{1}\right)_{r}^{S}$ & $\cdots$ & $\left(y_{j^{\prime}}\right)_{\eta}^{S}$ & $\cdots$ & $\left(y_{J^{\prime}}\right)_{\eta}^{S}$ & $\left(x_{1}\right)_{r}^{S}$ & $\cdots$ & $\left(x_{j}\right)_{r}^{S}$ & $\cdots$ & $\left(x_{J}\right)_{r}^{S}$ \\
\hline$\cdots$ & $\cdots$ & $\cdots$ & $\cdots$ & $\cdots$ & $\cdots$ & $\cdots$ & $\cdots$ & $\cdots$ & $\cdots$ & $\cdots$ \\
\hline$S$ & $\left(y_{1}\right)_{r}^{S}$ & $\cdots$ & $\left(y_{j^{\prime}}\right)_{\eta}^{S}$ & $\cdots$ & $\left(y_{J^{\prime}}\right)_{\eta}^{S}$ & $\left(x_{1}\right)_{r}^{S}$ & $\cdots$ & $\left(x_{j}\right)_{r}^{S}$ & $\cdots$ & $\left(x_{J}\right)_{r}^{S}$ \\
\hline
\end{tabular}


$\left(x_{j}\right)_{r}^{s}$, s. KV tarafından j. iç kriter için belirlenen öncelik sırasını ve $\left(\mathrm{y}_{\mathrm{j}}\right)_{\mathrm{r}}^{\mathrm{s}}$, s. KV tarafından $\mathrm{j}^{\prime}$. dış kriter için belirlenen öncelik sırasını gösterir.

\section{Adım 5: Her bir KV için öncelik matrislerinin oluşturulması}

$\mathrm{Bu}$ adımda ilk olarak; her bir KV için iç ve dış kriterlerin öncelik sırası Adım 4'de verilen Tablo 4 kullanılarak $\mathrm{x}_{(1)}^{\mathrm{s}}>$ $\mathrm{x}_{(2)}^{\mathrm{s}}>\cdots>\mathrm{x}_{(\mathrm{j})}^{\mathrm{s}}>\cdots>\mathrm{x}_{(\mathrm{m})}^{\mathrm{s}}$ ve $\mathrm{y}_{(1)}^{\mathrm{s}}>\mathrm{y}_{(2)}^{\mathrm{s}}>\cdots>\mathrm{y}_{\left(\mathrm{j}^{\prime}\right)}^{\mathrm{s}}>\cdots>$ $\mathrm{y}_{(\mathrm{n})}^{\mathrm{s}}$ şeklinde oluşturulur. $\mathrm{x}_{(\mathrm{j})}^{\mathrm{s}}$ ve $\mathrm{y}_{\left(\mathrm{j}^{\prime}\right)}^{\mathrm{s}} s$. uzman için $\mathrm{j}$. ve $\mathrm{j}^{\prime}$. sırada yer alan iç ve dış kriteri ifade etmektedir. Daha sonra; iç kriterler için her bir KV'nin öncelik matrisi $\left[A_{\mathrm{X}}^{\mathrm{S}}\right]_{\mathrm{mxm}}$ ve diş kriterler için $\left[A_{\mathrm{Y}}^{\mathrm{S}}\right]_{\mathrm{nxn}}$ olarak tanımlanır. $\mathrm{Bu}$ matrislerin elemanları $\left(a_{j d}\right)^{s}$ ve $\left(a_{j, f}\right)^{s}$ Eşitlik (4) kullanılarak hesaplanır.

$\left[A_{X}^{\mathrm{S}}\right]_{\mathrm{mxm}}$ ve $\left[A_{Y}^{\mathrm{s}}\right]_{\mathrm{nxn}}$ matrislerinde $\mathrm{j}=1,2, \ldots, \mathrm{m}$ ve $\mathrm{d}=1,2, \ldots, \mathrm{m}$ olmak üzere $x_{j j}=0, a_{j d}=1-a_{d j}, y_{j^{\prime} j}=0, j^{\prime}=1,2, \ldots, n, f=1,2, \ldots, n$ ve $a_{j / f}=1-a_{f j}, j \neq d$ ve $j^{\prime} \neq f$ şartları sağlanmaktadır.

$\left(a_{j d}\right)=\left\{\begin{array}{l}0, \operatorname{eğer~} x_{(j)}^{s}<x_{(d)}^{s} \\ 1, \operatorname{eğer~} x_{(j)}^{s}>x_{(d)}^{s}\end{array}\right\}$,

$\left(a_{j^{\prime} f}\right)^{s}=\left\{\begin{array}{l}0, \text { eğer } y_{\left(j^{\prime}\right)}^{s}<y_{(f)}^{s} \\ 1, \text { eğer } y_{\left(j^{\prime}\right)}^{s}>y_{(f)}^{s}\end{array}\right\}$

\section{Adım 6: İki farklı sıralama arasındaki uzaklığın hesaplanması}

Diş kriterler için $t^{\prime}$ tane olası matris olduğu durumda $A^{(\mathrm{t} t)}$ ve $\mathrm{A}^{(\mathrm{s})}$ matrisleri tarafindan tanımlanan iki farklı sıralama arasındaki uzaklığın ölçümü $\rho_{y}^{1}=\rho\left(\mathrm{A}^{(1)}, \mathrm{A}^{(\mathrm{s})}\right)$, Eşitlik (5)'deki gibi hesaplanır. Dış kriterler için aynı adımlar tekrarlanır.

$\rho_{\mathrm{y}}^{1}=\sum_{\mathrm{s}=1}^{\mathrm{s}} \sum_{\mathrm{j} /=1}^{\mathrm{n}} \sum_{\mathrm{f}=1}^{\mathrm{n}}\left|\mathrm{a}_{\mathrm{j} / \mathrm{f}}^{(1)}-\mathrm{a}_{\mathrm{j} / \mathrm{f}}^{(\mathrm{s})}\right|$

$\rho_{\mathrm{y}}^{2}=\sum_{\mathrm{s}=1}^{\mathrm{S}} \sum_{\mathrm{j} /=1}^{\mathrm{n}} \sum_{\mathrm{f}=1}^{\mathrm{n}}\left|\mathrm{a}_{\mathrm{j} / \mathrm{f}}^{(2)}-\mathrm{a}_{\mathrm{j} / \mathrm{f}}^{(\mathrm{s})}\right|$

$\rho_{\mathrm{y}}^{\mathrm{t} \prime}=\sum_{\mathrm{s}=1}^{\mathrm{S}} \sum_{\mathrm{j} \prime=1}^{\mathrm{n}} \sum_{\mathrm{f}=1}^{\mathrm{n}}\left|\mathrm{a}_{\mathrm{j}, \mathrm{f}}^{(\mathrm{t} /)}-\mathrm{a}_{\mathrm{j} / \mathrm{f}}^{(\mathrm{s})}\right|$

\section{Adım 7: Medyan matrisinin hesaplanması}

Eşitlik (6) kullanılarak Eşitlik (5) ile hesaplanan uzaklıkların minumum değeri yani $p_{x}$ bulunur ve minimum değeri veren matris medyan matrisi olarak kabul edilir. Medyan matrisinde ortaya çıkan kriter sıralaması iç kriterler için medyan öncelikli bileşenler olarak kabul edilir. Böylece Kemeny Medyan Yöntemi ile KV'lerin belirledikleri sıralamalar birleştirilerek; iç kriterler için tek bir öncelik sıralaması belirlenmiş olur. Dış kriterler için benzer adımlar tekrarlanır.

$p_{y}=\min \left(\rho_{y}^{1}, \rho_{y}^{2}, \ldots, \rho_{y}^{\mathrm{t} \prime}\right)$

Eşitlik (6)'yı sağlayan $\mathrm{KV} s^{*}$ 'ı kriter öncelik sıralaması $\mathrm{x}_{(1)}^{\mathrm{s*}}>\mathrm{x}_{(2)}^{\mathrm{s*}}>\cdots>\mathrm{x}_{(\mathrm{m})}^{\mathrm{s*}}$ ve $\mathrm{y}_{(1)}^{\mathrm{s*}}>\mathrm{y}_{(2)}^{\mathrm{s*}}>\cdots>\mathrm{y}_{(\mathrm{n})}^{\mathrm{s}} \quad$ şeklinde ortaya çıkar. Bu sıralamalar iç ve dış kriterlerin nihai öncelik siralamaları olarak kabul edilir.

\section{Adım 8: Kriter ağırlıklarının hesaplanması}

$\mathrm{Bu}$ adımda, Sıralama Uygunluk Göstergesi yöntemi kullanılarak kriterler için ağırlık değerleri belirlenmektedir. İlk olarak; Adım 5'de belirlenen kriterlere ait öncelik sıralamalarına $\left(\mathrm{x}_{(1)}^{\mathrm{s}}>\mathrm{x}_{(2)}^{\mathrm{s}}>\cdots>\mathrm{x}_{(\mathrm{j})}^{\mathrm{s}}>\cdots>\mathrm{x}_{(\mathrm{m})}^{\mathrm{s}}\right.$ ve $\mathrm{y}_{(1)}^{\mathrm{s}}>\mathrm{y}_{(2)}^{\mathrm{s}}>\cdots>$ $\left.\mathrm{y}_{\left(\mathrm{j}^{\prime}\right)}^{\mathrm{s}}>\cdots>\mathrm{y}_{(\mathrm{n})}^{\mathrm{s}}\right)$ uygun olarak Eşitlik (7) ve Eşitlik (8)'de gösterilen kriter ağırlıkları sıralaması elde edilir.

$\mathrm{w}_{\mathrm{x}_{(1)}}^{\mathrm{s*}} \geq \mathrm{w}_{\mathrm{x}_{(2)}}^{\mathrm{s*}} \geq \cdots \geq \mathrm{w}_{\mathrm{x}_{(\mathrm{j})}}^{\mathrm{s*}} \geq \cdots \geq \mathrm{w}_{\mathrm{x}_{(\mathrm{m})}}^{\mathrm{s*}}$

$\mathrm{w}_{\mathrm{y}_{(1)}}^{\mathrm{s*}} \geq \mathrm{w}_{\mathrm{y}_{(2)}}^{\mathrm{s*}} \geq \cdots \geq \mathrm{w}_{\mathrm{y}_{\left(\mathrm{j}^{\prime}\right)}}^{\mathrm{s*}} \geq \cdots \geq \mathrm{w}_{\mathrm{y}_{(\mathrm{n})}}^{\mathrm{s*}}$

Daha sonra, Eşitlik (7) ve Eşitlik (8)'deki sıralamalar dikkate alınarak ve $0 \leq w_{x_{j}}, w_{y_{j}} \leq 1$ olmak üzere Eşitlik (9) ve Eşitlik (10)'da gösterildiği gibi toplamları "1" olacak şekilde kriterlere ait ağırlık kombinasyonları belirlenir.

$\mathrm{w}_{\mathrm{x}_{1}}+\mathrm{w}_{\mathrm{x}_{2}}+\cdots+\mathrm{w}_{\mathrm{x}_{\mathrm{j}}}+\cdots+\mathrm{w}_{\mathrm{x}_{\mathrm{m}}}=1$

$\mathrm{w}_{\mathrm{y}_{1}}+\mathrm{w}_{\mathrm{y}_{2}}+\cdots+\mathrm{w}_{\mathrm{y}_{\mathrm{j}}}+\cdots+\mathrm{w}_{\mathrm{y}_{\mathrm{n}}}=1$

\section{3. Önerilen HTEA Tabanlı KEMIRA-M Yöntemi}

Önerilen HTEA tabanlı KEMIRA-M entegre yöntemi ile risk değerlendirme süreci 3 aşamadan oluşmaktadır.

Aşama 1: Verilerin toplanması

Aşama 2: HTEA yöntemi ile risk kriterlerinin önceliklerinin belirlenmesi

Aşama 3: KEMIRA-M yöntemi ile risk kriterlerinin ağırlıklarının hesaplanmas1.

\section{Araştırma Sonuçları ve Tartışma}

Bu uygulama çalışmasında önerilen HTEA tabanlı KEMIR$\mathrm{M}$ yöntemi kullanılarak acil servisler için risk değerlendirmesi yapılmıştır. Önerilen yöntem 3 aşamada uygulanmıştır.

\section{Aşama 1: Verilerin toplanması}

İlk olarak 3 doktor ve 2 hemşireden oluşan $5 \mathrm{KV}$ belirlenmiştir. Daha sonra, literatürdeki yayınlardan faydalanılarak hiyerarşik yap1 içerisinde 5 ana kriter ve 34 alt kriter olmak üzere 39 risk kriteri belirlenmiş ve KV'ler tarafindan onaylanmıştır ([18], [31], [28], [21], [5]; [33]). Kriterlerin hiyerarşik yapısı Şekil 1'de gösterilmiştir. Acil servislerde meydana gelebilecek risklere karşı alınabilecek önlemler;

- $\quad$ ğitim/seminer $\left(\mathrm{R}_{1}\right)$,

- Uyarı levhaları $\left(\mathrm{R}_{2}\right)$,

- Çalışma ortamı ergonomik düzenleme $\left(\mathrm{R}_{3}\right)$,

- Makine/ekipman kontrol/yenileme $\left(\mathrm{R}_{4}\right)$,

- Gerekli sağlık kontrolleri $\left(\mathrm{R}_{5}\right)$,

- Güvenlik kameraları/ güvenlik personeli $\left(\mathrm{R}_{6}\right)$,

- Kişisel koruyucu donanımların kullanımı $\left(\mathrm{R}_{7}\right)$,

- Çalışma şartlarının iyileştirilmesi $\left(\mathrm{R}_{8}\right)$

olarak belirlenmiş ve bu önlemler alternatif olarak ele alınmıştır.

Aşama 2: HTEA ile risk kriterlerinin önceliklerinin belirlenmesi.

$\mathrm{Bu}$ aşamada, herbir $\mathrm{KV}$ tarafindan risk kriterleri $\mathrm{O}$, Ş ve $\mathrm{S}$ derecelerine göre Tablo 1-3 kullanılarak değerlendirilmiştir. Daha sonra bu aşamada her KV için RÖS; Eşitlik (1) kullanılarak hesaplanmıştır. Hesaplanan RÖS değerleri büyükten küçüğe doğru sıralanarak KEMIRA-M yönteminde kriterlerin öncelikleri belirlenmiştir. Tablo 5'de herbir KV için belirlenen ana kriterlerin öncelikleri gösterilmiştir. 
Aşama 3: KEMIRA-M yöntemi ile risk kriterlerinin ağırlıklarının hesaplanması

Örnek olarak ana kriterler için KEMIRA-M yöntemi uygulanmıştır. Ana dış kriter grubu; Psikososyal sağlık sorunlarına neden olan riskler $\left(y_{1}\right)$, Güvensiz nöbet ortamı, vardiya ortamı ve iletişimle ilgili riskler $\left(y_{2}\right)$, Alerji ve enfeksiyon ile ilgili riskler $\left(\mathrm{y}_{3}\right)$ ve ana iç kriter grubu; Ergonomik riskler $\left(\mathrm{x}_{1}\right)$, Tıbbi cihaz, malzeme, araç ve gereç bağlantılı riskler $\left(\mathrm{x}_{2}\right)$ olarak sınıflandırılmıştır.

\section{Adım 1: Başlangıç karar matrisinin oluşturulması}

Eşitlik (2) kullanılarak Tablo 6'de gösterildiği gibi başlangıç karar matrisi oluşturulmuştur.

Tablo 6. Ana Kriterler İçin Başlangıç Karar Matrisi

\begin{tabular}{|l|l|l|l|l|l|}
\hline \multirow{2}{*}{ Alternatifler } & \multicolumn{3}{|c|}{$\begin{array}{c}\text { Diş Kriterler i } \\
(\mathrm{i}=1, \ldots, \mathrm{K})\end{array}$} & \multicolumn{2}{c|}{$\begin{array}{c}\text { İc Kriterler } \mathrm{i} \\
(\mathrm{i}=1, \ldots, \mathrm{K})\end{array}$} \\
\cline { 2 - 6 } & $\mathrm{y}_{1}^{(\mathrm{i})}$ & $\mathrm{y}_{2}^{(\mathrm{i})}$ & $\mathrm{y}_{3}^{(\mathrm{i})}$ & $\mathrm{x}_{1}^{(\mathrm{i})}$ & $\mathrm{x}_{2}^{(\mathrm{i})}$ \\
\hline $\mathrm{R}_{1}$ & 5 & 3 & 3 & 3 & 7 \\
\hline $\mathrm{R}_{2}$ & 1 & 5 & 1 & 5 & 7 \\
\hline $\mathrm{R}_{3}$ & 1 & 1 & 5 & 7 & 5 \\
\hline $\mathrm{R}_{4}$ & 3 & 1 & 1 & 3 & 7 \\
\hline $\mathrm{R}_{5}$ & 7 & 1 & 3 & 5 & 3 \\
\hline $\mathrm{R}_{6}$ & 3 & 7 & 1 & 1 & 1 \\
\hline $\mathrm{R}_{7}$ & 1 & 3 & 9 & 7 & 5 \\
\hline $\mathrm{R}_{8}$ & 7 & 7 & 3 & 5 & 3 \\
\hline
\end{tabular}

\section{Adım 2: Matrisin normalize edilmesi}

Eşitlik (3) kullanılarak matris normalize edilmektedir. Tablo 7'de gösterilmiştir.

Tablo 7. Ana Kriterler İçin Normalize Edilmiş Karar Matrisi

\begin{tabular}{|l|c|c|c|c|c|}
\hline \multirow{2}{*}{ Alternatifler } & \multicolumn{3}{|c|}{$\begin{array}{c}\text { Dış Kriterler i } \\
(\mathrm{i}=1, \ldots, \mathrm{K})\end{array}$} & \multicolumn{2}{c|}{$\begin{array}{c}\text { Ic Kriterler } \mathrm{i} \\
(\mathrm{i}=1, \ldots, \mathrm{K})\end{array}$} \\
\cline { 2 - 6 } & $\mathrm{y}_{1}^{(\mathrm{i}) *}$ & $\mathrm{y}_{2}^{(\mathrm{i}) *}$ & $\mathrm{y}_{3}^{(\mathrm{i}) *}$ & $\mathrm{x}_{1}^{(\mathrm{i}) *}$ & $\mathrm{x}_{2}^{(\mathrm{i}) *}$ \\
\hline $\mathrm{R}_{1}$ & 0,417 & 0,250 & 0,257 & 0,217 & 0,476 \\
\hline $\mathrm{R}_{2}$ & 0,083 & 0,417 & 0,086 & 0,361 & 0,476 \\
\hline $\mathrm{R}_{3}$ & 0,083 & 0,083 & 0,429 & 0,505 & 0,340 \\
\hline $\mathrm{R}_{4}$ & 0,250 & 0,083 & 0,086 & 0,217 & 0,476 \\
\hline $\mathrm{R}_{5}$ & 0,583 & 0,083 & 0,257 & 0,361 & 0,204 \\
\hline $\mathrm{R}_{6}$ & 0,250 & 0,583 & 0,086 & 0,072 & 0,068 \\
\hline $\mathrm{R}_{7}$ & 0,083 & 0,250 & 0,772 & 0,505 & 0,340 \\
\hline $\mathrm{R}_{8}$ & 0,583 & 0,583 & 0,257 & 0,361 & 0,204 \\
\hline
\end{tabular}

Adım 3: HTEA yönteminde belirlenen önceliklere göre kriter önceliklerinin düzenlenmesi

Tablo 8'de gösterildiği gibi kriter öncelikleri oluşturulmuştur.

Tablo 8. Ana Kriterler Iç̧in Kriter Öncelikleri

\begin{tabular}{|c|l|l|l|l|l|}
\hline \multirow{2}{*}{ Kriter } & \multicolumn{3}{|c|}{ Dış Kriterler $\mathbf{i}(\mathrm{i}=1, \ldots}$, & \multicolumn{2}{|c|}{$\begin{array}{l}\text { Iç Kriterler } \mathbf{i} \\
(\mathrm{i}=1, \ldots, \mathrm{K})\end{array}$} \\
\cline { 2 - 6 } $\boldsymbol{K}_{\boldsymbol{s}}$ & $\mathrm{y}_{1}^{(\mathrm{i})}$ & $\mathrm{y}_{2}^{(\mathrm{i})}$ & $\mathrm{y}_{3}^{(\mathrm{i})}$ & $\mathrm{x}_{1}^{(\mathrm{i})}$ & $\mathrm{x}_{2}^{(\mathrm{i})}$ \\
\hline $\mathrm{KV}_{1}$ & 3 & 1 & 2 & 2 & 1 \\
\hline $\mathrm{KV}_{2}$ & 3 & 1 & 2 & 2 & 1 \\
\hline $\mathrm{KV}_{3}$ & 3 & 2 & 1 & 2 & 1 \\
\hline $\mathrm{KV}_{4}$ & 2 & 1 & 3 & 2 & 1 \\
\hline $\mathrm{KV}_{5}$ & 2 & 1 & 3 & 2 & 1 \\
\hline
\end{tabular}

Adım 4: Uzman sıralamalarına göre öncelik kriteri matrislerinin oluşturulması

İlk olarak Tablo 9'da gösterildiği gibi her bir KV için kriter öncelikleri oluşturulmuştur.

Tablo 9. Her Bir KV İçin Kriter Öncelikleri

\begin{tabular}{|c|c|c|}
\hline $\mathbf{K V}_{\mathbf{s}}$ & Dış Kriterler & İç Kriterler \\
\hline $\mathrm{KV}_{1}$ & $\mathrm{y}_{2}^{(\mathrm{i})}>\mathrm{y}_{3}^{(\mathrm{i})}>\mathrm{y}_{1}^{(\mathrm{i})}$ & $\mathrm{x}_{2}^{(\mathrm{i})}>\mathrm{x}_{1}^{(\mathrm{i})}$ \\
\hline $\mathrm{KV}_{2}$ & $\mathrm{y}_{2}^{(\mathrm{i})}>\mathrm{y}_{3}^{(\mathrm{i})}>\mathrm{y}_{1}^{(\mathrm{i})}$ & $x_{2}^{(i)}>x_{1}^{(i)}$ \\
\hline $\mathrm{KV}_{3}$ & $\mathrm{y}_{3}^{(\mathrm{i})}>\mathrm{y}_{2}^{(\mathrm{i})}>\mathrm{y}_{1}^{(\mathrm{i})}$ & $\mathrm{x}_{2}^{(\mathrm{i})}>\mathrm{x}_{1}^{(\mathrm{i})}$ \\
\hline $\mathrm{KV}_{4}$ & $\mathrm{y}_{2}^{(\mathrm{i})}>\mathrm{y}_{1}^{(\mathrm{i})}>\mathrm{y}_{3}^{(\mathrm{i})}$ & $\mathrm{x}_{2}^{(\mathrm{i})}>\mathrm{x}_{1}^{(\mathrm{i})}$ \\
\hline $\mathrm{KV}_{5}$ & $\mathrm{y}_{2}^{(\mathrm{i})}>\mathrm{y}_{1}^{(\mathrm{i})}>\mathrm{y}_{3}^{(\mathrm{i})}$ & $\mathrm{x}_{2}^{(\mathrm{i})}>\mathrm{x}_{1}^{(\mathrm{i})}$ \\
\hline
\end{tabular}

Ana dış kriterler için hesaplamalar aşağıda gösterilmiştir.

Eşitlik (4) kullanılarak uzman sıralamalarına göre öncelik kriteri matrisleri oluşturulmuştur.

$$
\begin{aligned}
& {\left[A_{y}^{(1)}\right]_{3 * 3}=\left[A_{y}^{(2)}\right]_{3 * 3}=\mathrm{y}_{2}^{(\mathrm{i})}>\mathrm{y}_{3}^{(\mathrm{i})}>\mathrm{y}_{1}^{(\mathrm{i})}=\left[\begin{array}{lll}
0 & 0 & 0 \\
1 & 0 & 1 \\
1 & 0 & 0
\end{array}\right]} \\
& {\left[A_{y}^{(3)}\right]_{3 * 3}=\mathrm{y}_{3}^{(\mathrm{i})}>\mathrm{y}_{2}^{(\mathrm{i})}>\mathrm{y}_{1}^{(\mathrm{i})}=\left[\begin{array}{lll}
0 & 0 & 0 \\
1 & 0 & 0 \\
1 & 1 & 0
\end{array}\right]} \\
& {\left[A_{y}^{(4)}\right]_{3 * 3}=\left[A_{y}^{(5)}\right]_{3 * 3}=\mathrm{y}_{2}^{(\mathrm{i})}>\mathrm{y}_{1}^{(\mathrm{i})}>\mathrm{y}_{3}^{(\mathrm{i})}=\left[\begin{array}{lll}
0 & 0 & 1 \\
1 & 0 & 1 \\
0 & 0 & 0
\end{array}\right]}
\end{aligned}
$$

Adım 5: Kriterlere göre muhtemel matrislerin oluşturulması

Eşitlik (4) kullanılarak muhtemel seçenekler için öncelik kriteri matrisleri oluşturulmaktadır. 5 uzman tarafından belirlenen öncelik matrisleri yukarıda gösterildiği gibidir. Ancak $n=3$ olduğundan medyan matrisi $3 !=6$ olası matris arasından araştırılacaktır. 6 matris Tablo 10’da gösterildiği gibidir. 


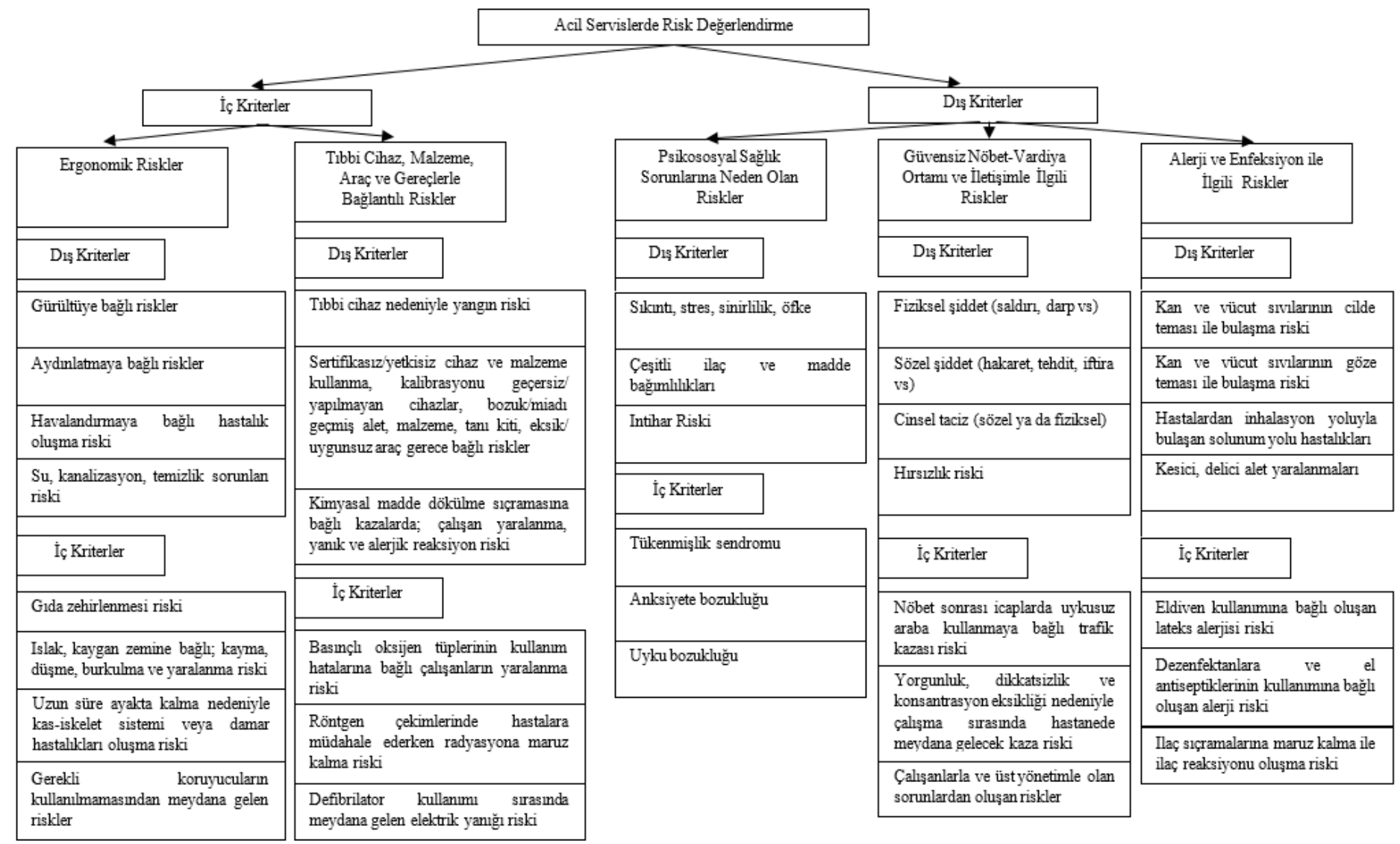

Şekil 1. Kriterlerin Hiyerarşik Yapısı

Tablo 5. HTEA Yöntemi İle Ana Kriterlerin Önceliklendirilmesi

\begin{tabular}{|c|c|c|c|c|c|c|c|c|c|c|c|c|c|c|c|c|c|c|c|c|}
\hline & \multicolumn{5}{|c|}{ Olasilık } & \multicolumn{5}{|c|}{ Şiddet } & \multicolumn{5}{|c|}{ Saptanabilirlik } & \multicolumn{5}{|c|}{ RÖS } \\
\hline & $\mathbf{K V _ { 1 }}$ & $\mathbf{K V}_{2}$ & $\mid \mathrm{KV}_{\mathbf{3}}$ & \begin{tabular}{|l|}
$\mathbf{K V}_{4}$ \\
\end{tabular} & $\mathrm{KV}_{5}$ & $\mathbf{K V _ { 1 }}$ & \begin{tabular}{|l|}
$\mathbf{K V}$ \\
\end{tabular} & $\mathbf{K V _ { 3 }}$ & $\mathbf{K V} \mathbf{V}_{4}$ & $\mathbf{K V} \mathbf{V}_{5}$ & $K V_{1}$ & $\mathbf{K V} \mathbf{V}_{2}$ & $\mathrm{KV}_{3}$ & $\mathbf{K V}_{4}$ & $\mathrm{KV}_{5}$ & $\mathbf{K V _ { 1 }}$ & $\mathbf{K V _ { 2 }}$ & $\mathrm{KV}_{3}$ & $\mathbf{K V}_{4}$ & $\mathrm{KV}_{5}$ \\
\hline \multicolumn{21}{|l|}{ DIŞ KRİTERLER } \\
\hline $\begin{array}{l}\text { Psikososyal Sağllk Sorunlarına } \\
\text { Neden Olan Riskler }\left(\mathrm{y}_{1}\right)\end{array}$ & 5 & 6 & 7 & 9 & 5 & 5 & 4 & 4 & 6 & 6 & 4 & 5 & 6 & 6 & 5 & 100 & 120 & 168 & 324 & 150 \\
\hline $\begin{array}{l}\text { Güvensiz Nöbet Ortamı, Vardiya } \\
\text { Ortamı ve } \\
\text { Riskler }\left(\mathrm{y}_{2}\right)\end{array}$ & 6 & 5 & 5 & 8 & 5 & 8 & 6 & 5 & 7 & 6 & 8 & 9 & 8 & 7 & 6 & 384 & 270 & 200 & 392 & 180 \\
\hline $\begin{array}{l}\text { Alerji ve Enfeksiyon ile İlgili } \\
\text { Riskler( }\left(\mathrm{y}_{3}\right)\end{array}$ & 7 & 5 & 6 & 6 & 4 & 6 & 4 & 5 & 3 & 3 & 6 & 8 & 7 & 8 & 6 & 252 & 160 & 210 & 144 & 72 \\
\hline \multicolumn{21}{|l|}{ İÇ KRITTERLER } \\
\hline Ergonomik Riskler( $\left(\mathrm{x}_{1}\right)$ & 5 & 5 & 6 & 4 & 5 & 6 & 5 & 5 & 5 & 4 & 4 & 3 & 3 & 4 & 3 & 120 & 75 & 90 & 80 & 60 \\
\hline $\begin{array}{l}\text { Tibbi Cihaz, Malzeme, Araç ve } \\
\text { Gereç Bağlantılı Riskler }\left(\mathrm{x}_{2}\right)\end{array}$ & 4 & 4 & 5 & 3 & 3 & 6 & 7 & 7 & 7 & 6 & 8 & 7 & 6 & 8 & 5 & \begin{tabular}{|l|l|}
192 \\
\end{tabular} & 196 & 210 & 168 & 90 \\
\hline
\end{tabular}


Tablo 10. Olası Seçenekler Için Öncelik Kriteri Matrisleri, Dış Kriterler ve $\rho_{y}^{\text {t’ }}$ Değerleri

\begin{tabular}{|c|c|c|c|c|}
\hline & & $\mathbf{K V}_{\mathbf{s}}$ & & $\mathbf{K V}_{\mathbf{s}}$ \\
\hline \multirow[t]{2}{*}{ Permütasyon } & $(1,2,3)$ & \multirow[t]{2}{*}{-} & $(1,3,2)$ & \multirow[t]{2}{*}{-} \\
\hline & $y_{1}>y_{2}>y_{3}$ & & $y_{1}>y_{3}>y_{2}$ & \\
\hline$A$ matrisi & $\begin{array}{l}{\left[A_{y}^{(1)}\right]_{3 * 3}} \\
=\left[\begin{array}{lll}0 & 1 & 1 \\
0 & 0 & 1 \\
0 & 0 & 0\end{array}\right]\end{array}$ & & $\begin{array}{l}{\left[A_{y}^{(2)}\right]_{3 * 3}} \\
=\left[\begin{array}{lll}0 & 1 & 1 \\
0 & 0 & 0 \\
0 & 1 & 0\end{array}\right]\end{array}$ & \\
\hline$\rho$ & $\rho_{y}^{8}=18$ & & $\rho_{y}^{6}=24$ & \\
\hline \multirow[t]{2}{*}{ Permütasyon } & $(2,1,3)$ & \multirow{2}{*}{$\begin{array}{l}\mathrm{KV}_{4} \\
=\mathrm{KV}_{5}\end{array}$} & $(2,3,1)$ & \multirow{2}{*}{$\begin{array}{l}\mathrm{KV}_{1} \\
=\mathrm{KV}_{2}\end{array}$} \\
\hline & $y_{2}>y_{1}>y_{3}$ & & $y_{2}>y_{3}>y_{1}$ & \\
\hline$A$ matrisi & $\begin{array}{l}{\left[A_{y}^{(3)}\right]_{3 * 3}} \\
=\left[\begin{array}{lll}0 & 0 & 1 \\
1 & 0 & 1 \\
0 & 0 & 0\end{array}\right]\end{array}$ & & $\begin{array}{l}{\left[A_{y}^{(4)}\right]_{3 * 3}} \\
=\left[\begin{array}{lll}0 & 0 & 0 \\
1 & 0 & 1 \\
1 & 0 & 0\end{array}\right]\end{array}$ & \\
\hline$\rho$ & $\rho_{y}^{4,5}=8$ & & $\rho_{y}^{1,2}=6$ & \\
\hline \multirow[t]{2}{*}{ Permutasyon } & $(3,1,2)$ & \multirow[t]{2}{*}{-} & $(3,2,1)$ & \multirow{2}{*}{$\mathrm{KV}_{3}$} \\
\hline & $y_{3}>y_{1}>y_{2}$ & & $\begin{array}{l}y_{3}>y_{2} \\
>y_{1}\end{array}$ & \\
\hline$A$ matrix & $\begin{array}{l}{\left[A_{y}^{(5)}\right]_{3 * 3}} \\
=\left[\begin{array}{lll}0 & 1 & 0 \\
0 & 0 & 0 \\
1 & 1 & 0\end{array}\right]\end{array}$ & & $\begin{array}{l}{\left[A_{y}^{(6)}\right]_{3 * 3}} \\
=\left[\begin{array}{lll}0 & 0 & 0 \\
1 & 0 & 0 \\
1 & 1 & 0\end{array}\right]\end{array}$ & \\
\hline$\rho$ & $\rho_{y}^{7}=22$ & & $\rho_{y}^{3}=12$ & \\
\hline
\end{tabular}

\section{Adım 6: İki farklı sıralama arasındaki uzaklığın hesaplanması}

Eşitlik (5) kullanılarak oluşturulan iki farklı sıralama arasındaki uzaklıklar hesaplanmaktadır.

$$
\begin{aligned}
& \rho_{\mathrm{y}}^{1}=\sum_{\mathrm{S}=1}^{5} \rho\left(\mathrm{A}^{1}, \mathrm{~A}^{(\mathrm{S})}\right)=0+0+2+2+2=6 \\
& \rho_{\mathrm{y}}^{2}=\sum_{\mathrm{S}=1}^{5} \rho\left(\mathrm{A}^{2}, \mathrm{~A}^{(\mathrm{S})}\right)=0+0+2+2+2=6 \\
& \rho_{\mathrm{y}}^{3}=\sum_{\mathrm{S}=1}^{5} \rho\left(\mathrm{A}^{3}, \mathrm{~A}^{(\mathrm{S})}\right)=2+2+0+4+4=12 \\
& \rho_{\mathrm{y}}^{4}=\sum_{\mathrm{S}=1}^{5} \rho\left(\mathrm{A}^{4}, \mathrm{~A}^{(\mathrm{S})}\right)=2+2+4+0+0=8 \\
& \rho_{\mathrm{y}}^{5}=\sum_{\mathrm{S}=1}^{5} \rho\left(\mathrm{A}^{5}, \mathrm{~A}^{(\mathrm{S})}\right)=2+2+4+0+0=8 \\
& \rho_{\mathrm{y}}^{6}=\sum_{\mathrm{S}=1}^{5} \rho\left(\mathrm{A}^{6}, \mathrm{~A}^{(\mathrm{S})}\right)=6+6+4+4+4=24 \\
& \rho_{\mathrm{y}}^{7}=\sum_{\mathrm{S}=1}^{5} \rho\left(\mathrm{A}^{7}, \mathrm{~A}^{(\mathrm{S})}\right)=4+4+2+6+6=22 \\
& \rho_{\mathrm{y}}^{8}=\sum_{\mathrm{S}=1}^{5} \rho\left(\mathrm{A}^{8}, \mathrm{~A}^{(\mathrm{S})}\right)=4+4+6+2+2=18
\end{aligned}
$$

\section{Adım 7: Medyan matrisinin hesaplanması}

Eşitlik (6) kullanılarak medyan matrisi hesaplanmaktadır. Minimum toplam değer olan 6 değerine $A^{1}$ ve $A^{2}$ matrislerinde ulaşılmıştır. Bu da dış faktörler arasında en iyi olan medyan değeri $K V_{1}=K V_{2}=(2,3,1)$ yani $\mathrm{y}_{2}^{(\mathrm{i})}>\mathrm{y}_{3}^{(\mathrm{i})}>\mathrm{y}_{1}^{(\mathrm{i})} \mathrm{dir}$.

\section{Adım 8: Kriter ağırlıklarının hesaplanması}

Eşitlik (8) ve Eşitlik (10) kullanılarak kriter ağırlıkları Tablo 11 'deki gibi bulunmuştur. Tablo 11'e bakıldığında en önemli ana dış kriter grubu güvensiz nöbet-vardiya ortamı ve iletişimle ilgili riskler olarak belirlenirken; en önemli ana iç kriter grubu ise tıbbi cihaz, malzeme, araç ve gereçlerle bağlantılı riskler ile ergonomik riskler olarak ortaya çıkmıştır. Bununla birlikte; alt dış kriterlerden en önemli kriterler tıbbi cihaz nedeniyle yangın riski, kimyasal madde dökülme, sıçramasına bağlı kazalarda çalışan yaralanma, yanık ve alerjik reaksiyon riski, fiziksel şiddet ve sözel şiddet iken en önemli alt iç kriter ise uzun süre ayakta kalma nedeniyle, kas- iskelet sistemi veya damar hastalıkları oluşma riski olarak belirlenmiştir. Eğitim ve seminerler, çalışma ortamının ergonomik açıdan düzenlenmesi, kişisel koruyucu donanımların kullanılması ve çalışma şartlarının iyileştirilmesi önlemleri de ilk sırada alınması gereken önlemler olarak belirlenmiştir.

\section{Sonuç ve Öneriler}

$\mathrm{Bu}$ çalışmada acil servislerde risk değerlendirmesi için HTEA tabanlı KEMIRA-M yöntemi önerilmiştir. KEMIRA-M yönteminde kriter öncelikleri aşamasında HTEA yöntemi kullanılarak KEMIRA-M yöntemi geliştirilmiştir. Kriter öncelikleri geçerliliği bilinen skalalara bağlı olarak hesaplanan RÖS değeri ile belirlenerek KV'lerden kaynaklanan sübjektiflik azaltılmaya çalışılmıştır. Bununla birlikte acil servilerde sağlık personelinin verimliliğini ve iş sağlığını etkileyen en önemli risk kriterleri ortaya çıkarılmıştır.

Önerilen HTEA tabanlı KEMIRA-M entegre yöntemi insan duygu ve düşüncelerinden, çalışma ortamından ve eksik verilerden kaynaklanan belirsizliklerinde risk değerlendirmede dikkate alınması için bulanık küme teorisi kullanılarak yeniden modellenebilir. KEMIRA-M yönteminde başlangıç aşamasında kriter önceliklerinin belirlenmesi ve daha sonraki aşamalarda kriter ağırlıklarının belirlenmesinde ortaya çıkan subjektifliğin azaltılması için farklı yöntemlerle entegre edilebilir. KEMIRA-M yöntemiyle alternatflerin sıralaması yapılabilir. Son olarak HTEA yöntemi yerine farklı risk değerlendirme yöntemleri kullanılabileceği öngörülmektedir.

\section{Teșekkür}

Karar vericilere ve hastane personeline desteklerinden dolay1 çok teşekkür ederiz. 
Tablo 11. HTEA Tabanlı KEMIRA-M Yöntemi ile Bulunan Ana ve Alt Kriter A ğırlıkları

\begin{tabular}{|c|c|c|c|c|c|}
\hline & $\begin{array}{c}\text { Ana Kriter } \\
\text { Ağırlığı }\end{array}$ & $\begin{array}{l}\text { Ana Kriter } \\
\text { Ağırlığı } \\
\text { Normalize } \\
\end{array}$ & $\begin{array}{l}\text { Alt Kriter } \\
\text { Ağırlığı }\end{array}$ & $\begin{array}{l}\text { Alt Kriter } \\
\text { Ağırlığı } \\
\text { Normalize } \\
\end{array}$ & $\begin{array}{c}\text { Alt Kriter } \\
\text { Global } \\
\text { Ağırlı̆̆ı }\end{array}$ \\
\hline \multicolumn{6}{|l|}{ ANA-DIŞ KRITERLER } \\
\hline Psikososyal Sağlık Sorunlarına Neden Olan Riskler & 0,300 & $\mathbf{0 , 1 5 0}$ & & & \\
\hline \multicolumn{6}{|l|}{ Alt Dış Kriterler } \\
\hline Sıkıntı, stres, sinirlilik, öfke & & & 0,500 & 0,250 & 0,038 \\
\hline Çeşitli ilaç ve madde bağımlılıkları & & & 0,000 & 0,000 & 0,000 \\
\hline İntihar riski & & & 0,500 & 0,250 & 0,038 \\
\hline \multicolumn{6}{|l|}{ Alt İç Kriterler } \\
\hline Tükenmişlik sendromu & & & 0,300 & 0,150 & 0,023 \\
\hline Anksiyete bozukluğu & & & 0,300 & 0,150 & 0,023 \\
\hline Uyku bozukluğu & & & 0,400 & 0,200 & 0,030 \\
\hline Genel Toplam & & & 2,000 & 1,000 & \\
\hline $\begin{array}{l}\text { Güvensiz Nöbet-Vardiya Ortamı ve İletişimle İlgili } \\
\text { Riskler }\end{array}$ & 0,400 & 0,200 & & & \\
\hline \multicolumn{6}{|l|}{ Alt Dış Kriterler } \\
\hline Fiziksel şiddet & & & 0,500 & 0,250 & 0,050 \\
\hline Sözel şiddet & & & 0,500 & 0,250 & 0,050 \\
\hline Cinsel taciz & & & 0,000 & 0,000 & 0,000 \\
\hline Hırsızlık Riski & & & 0,000 & 0,000 & 0,000 \\
\hline \multicolumn{6}{|l|}{ Alt İç Kriterler } \\
\hline $\begin{array}{l}\text { Nöbet sonrası icaplarda uykusuz araba kullanmaya } \\
\text { bağl1 } \\
\text { trafik kazası riski }\end{array}$ & & & 0,500 & 0,250 & 0,050 \\
\hline $\begin{array}{l}\text { Yorgunluk, dikkatsizlik ve konsantrasyon eksikliği } \\
\text { nedeniyle çalış̧a sırasında hastanede meydana } \\
\text { gelebilecek kaza riski }\end{array}$ & & & 0,000 & 0,000 & 0,000 \\
\hline Çalışanlarla ve üst yönetimle olan oluşan riskler & & & 0,500 & 0,250 & 0,050 \\
\hline Alerji Ve Enfeksiyon İle İlgili Riskler & 0,300 & 0,150 & & & \\
\hline \multicolumn{6}{|l|}{ Alt Dış Kriterler } \\
\hline Kan ve vücut sıvılarının cilde teması ile bulaşma riski & & & 0,200 & 0,100 & 0,015 \\
\hline Kan ve vücut sıvılarının göze teması ile bulaşma riski & & & 0,200 & 0,100 & 0,015 \\
\hline $\begin{array}{l}\text { Hastalardan inhalasyon yoluyla bulaşan solunum yolu } \\
\text { hastalıkları }\end{array}$ & & & 0,300 & 0,150 & 0,023 \\
\hline Kesici, delici alet yaralanmaları & & & 0,300 & 0,150 & 0,023 \\
\hline \multicolumn{6}{|l|}{ Alt İç Kriterler } \\
\hline Eldiven kullanımına bağlı oluşan lateks alerjisi riski & & & 0,400 & 0,200 & 0,030 \\
\hline $\begin{array}{l}\text { Dezenfektanlara ve el antiseptiklerinin kullanımına } \\
\text { bağlı } \\
\text { oluşan alerji riski }\end{array}$ & & & 0,300 & 0,150 & 0,023 \\
\hline $\begin{array}{l}\text { İlaç sıçramalarına maruz kalma ile ilaç reaksiyonu } \\
\text { oluşma } \\
\text { riski }\end{array}$ & & & 0,300 & 0,150 & 0,023 \\
\hline \multicolumn{6}{|l|}{ ANA-IÇ KRITERLER } \\
\hline Ergonomik Riskler & $\mathbf{0 , 5 0 0}$ & $\mathbf{0 , 2 5 0}$ & & & \\
\hline \multicolumn{6}{|l|}{ Alt Dış Kriterler } \\
\hline Gürülttüye bağlı riskler & & & 0,300 & 0,150 & 0,038 \\
\hline Aydınlatmaya bağlı riskler & & & 0,300 & 0,150 & 0,038 \\
\hline Havalandırmaya bağlı hastalık oluşma riski & & & 0,300 & 0,150 & 0,038 \\
\hline Su, kanalizasyon ve temizlik sorunları riski & & & 0,100 & 0,050 & 0,013 \\
\hline \multicolumn{6}{|l|}{ Alt İç Kriterler } \\
\hline Gida zehirlenmesi riski & & & 0,100 & 0,050 & 0,013 \\
\hline $\begin{array}{l}\text { Islak, kaygan zemine bağli; kayma, düşme, burkulma ve } \\
\text { yaralanma riski }\end{array}$ & & & 0,200 & 0,100 & 0,025 \\
\hline Uzun süre ayakta kalma nedeniyle, kas- iskelet sistemi & & & 0,500 & 0,250 & 0,063 \\
\hline
\end{tabular}




\begin{tabular}{|c|c|c|c|c|c|}
\hline veya damar hastalıkları oluşma riski & & & & & \\
\hline $\begin{array}{l}\text { Gerekli koruyucuların kullanılmamasından meydana } \\
\text { gelen riskler }\end{array}$ & & & 0,200 & 0,100 & 0,025 \\
\hline $\begin{array}{l}\text { Tibbi Cihaz, Malzeme, Araç Ve Gereç Bağlantılı } \\
\text { Riskler }\end{array}$ & $\mathbf{0 , 5 0 0}$ & 0,250 & & & \\
\hline Alt Dış Kriterler & & & & & \\
\hline Tibbi cihaz nedeniyle yangin riski & & & 0,400 & 0,200 & 0,050 \\
\hline $\begin{array}{l}\text { Sertifikası/ yetkisiz cihaz ve malzeme kullanma vs. ile } \\
\text { ilgili riskler }\end{array}$ & & & 0,200 & 0,100 & 0,025 \\
\hline $\begin{array}{l}\text { Kimyasal madde dökülme, sıçramasına bağlı kazalarda; } \\
\text { çalışan yaralanma, yanık ve alerjik reaksiyon riski }\end{array}$ & & & 0,400 & 0,200 & 0,050 \\
\hline Alt İç Kriterler & & & & & \\
\hline $\begin{array}{l}\text { Basınçlı oksijen tüplerinin kullanım hatalarına bağlı } \\
\text { çalışanların yaralanma riski }\end{array}$ & & & 0,300 & 0,150 & 0,038 \\
\hline $\begin{array}{l}\text { Röntgen çekimlerinde hastalara müdahale ederken } \\
\text { radyasyona maruz kalma riski }\end{array}$ & & & 0,400 & 0,200 & 0,050 \\
\hline $\begin{array}{l}\text { Defibrilatör kullanımı sırasında meydana gelen elektrik } \\
\text { yanığı riski }\end{array}$ & & & 0,300 & 0,150 & 0,038 \\
\hline
\end{tabular}

\section{Kaynakça}

[1] Aksay, K. and Orhan, F. (2013).Hastanelerde inovasyon sürecinin risk yönetimi bağlamında değerlendirilmesi: bir model önerisi. Dicle Üniversitesi İktisadi ve İdari Bilimler Fakültesi Dergisi, 2(3), 10-23.

[2] Aksay, K., Orhan, F. and Kurutkan, M. N., (2012). Sağlık hizmetlerinde bir risk yönetimi tekniği olarak fmea: laboratuvar sürecine yönelik bir uygulama. Sağlikta Performans Ve Kalite Dergisi, 4(2), 121-142.

[3] Arslan, N. and Delice, E.K., (2020). KEMIRA-M yöntemi ile kişisel kullanıcılar için drone seçimi: bir uygulama. Endüstri Mühendisliği 31(2), 159-179.

[4] Arslan, N., (2020).HTEA Tabanlı Fucom \& Kemira-M Entegre Yöntemi İle Sağlık Sektöründe Risk Değerlendirme. Yüksek Lisans Tezi, Atatürk Üniversitesi Fen Bilimleri Enstitüsü, Erzurum.

[5] Beşer, A., (2012). Sağlık çalışanlarının sağlık riskleri ve yönetimi. Dokuz Eylül Üniversitesi Hemşirelik Yüksekokulu Elektronik Dergisi, 5 (1), 39-44.

[6] Bol, P., Gül, G. and Erbaycu A. E., (2013).Hasta-hekim iletişimindeki eksiklik ve hataların ortaya konmasında FMEA model analizinin katkısı. İzmir Göğüs Hastanesi Dergisi, XXVII(3), 181-191.

[7] Carter, A. J. E., Gould, J. B., Vanberkel, P., Jensen, J. L., Cook, J., Carrigan, S., Wheatley, M.R. and Travers, A. H., (2015). Offload zones to mitigate emergency medical services (EMS) offload delay in the emergency department: a process map and hazard analysis. Canadian Journal of Emergency Medicine (CJEM), 17(6), 670-678.

[8] Delice, E. and Can, G. F., (2020). A new approach for ergonomic risk assessment integrating KEMIRA, best_worst and MCDM methods. Metodologies and Aplication.

[9] Delice, E.K. and Zegerek, S., (2016). Ranking occupational risk levels of emergency departments using a new fuzzy mcdm model: a case study in Turkey. Applied Mathematics \& Information Sciences An International Journal, 10(6), 2345-2356.

[10] Demirkan, C. B., (2015). Sağlık Hizmetleri Sektöründe Risk Değerlendirmesi: Hastane Merkez Laboratuvarı Örneği. Uzmanlık Tezi, Trakya Üniversitesi Tıp Fakültesi Halk Sağlığı Anabilim Dalı, Edirne
[11]Habli, I., Jia, Y., White, S., Gabriel, G., Lawton, T., Sujan, M. and Tomsett, C., (2019). Development and piloting of a software tool to facilitate proactive hazard and risk analysis of health information technology. Health Informatics Journal, 00(0), 1-20.

[12]Kırılmaz, H., Yorgun, S. and Atasoy, A., (2016). Sağlık çalışanlarında psikososyal risk faktörlerini belirlemeye yönelik bir araştırma. International Journal of Cultural and Social Studies (IntJCSS), 2(SI 1), 66-82.

[13]Kış, Ö., Can, G. F. ve Toktaş, P, (2020). Warehouse location selection for an electricity distribution company by KEMIRA-M method. Pamukkale Üniversitesi Mühendislik Bilimleri Dergisi, 26(1), 227-240.

[14]Kosareva, N., Zavadskas, E.K., Krylovas, A. ve Dadelo S, (2016). Personnel ranking and selection problem solution by application of KEMIRA method. International Journal of Computers Communications \& Control,11(1),51-66.

[15]Krylovas, A., Zavadskas, E. K. and Kosareva, N., (2016). Multiple criteria decision-making KEMIRA-M method for solution of location alternatives. Economic Research, 29(1), 50-65.

[16]Krylovas, A., Dadelo, S., Kosareva, N. and Zavadskas, E. K., (2017). ENTROPY-KEMIRA approach for mcdm problem solution in human resources selection task. International Journal of Information Technology \& Decision Making, 16(05), 1183-1209.

[17]Krylovas, A., Kosareva, N. and Zavadskas E.K., (2016). Statistical analysis of KEMIRA type weights balancing methods. Romanian Journal of Economic Forecasting, XIX (3), 19-39.

[18]Özkan, Ö., (2005). Hastanede Çalışan Hemşirelerin İş ve Çalışma Ortamı Tehlike ve Riskleri ile Risk Algılarını Saptanması. Yükek Lisans Tezi, Hacettepe Üniversitesi Sağlık Bilimleri Enstitüsü, Ankara.

[19]Özkılıç, Ö., (2005). İş Sağlığı ve Güvenliği, Yönetim Sistemleri ve Risk Değerlendirme Metodolojileri, Türkiye İşveren Sendikaları Konfederasyonu, 219, Türkiye.

[20]Pakdil, F., Toktaş, P. and Can, G. F., (2021). Six sigma project prioritization and selection: a multi- criteria decision making approach in healthcare industry. International Journal of Lean Six Sigma, 12(3), 553-578. 
[21]Parlar, S., (2008). Sağlık çalışanlarında göz ardı edilen bir durum: sağlıklı çalışma ortamı. TAF Preventive Medicine Bulletin, 7(6), 547-54.

[22]Redfern, E., Brown, R. and Vincent, C. A., (2009). Improving communication in the emergency department. Emerg Med J, 26(9), 658-661.

[23]Sarıçalı, G. and Kundakcı, N., (2017). Forklift alternatiflerinin KEMIRA-M yöntemi ile değerlendirilmesi. Optimum Ekonomi ve Yönetim Bilimleri Dergisi, 4(1), 3553.

[24]Sarıçalı, G., (2018). Çok Kriterli Karar Verme Yöntemlerinden KEMIRA-M ve COPRAS Yöntemlerinin Mermer İşletmesinde Makine Seçim Sürecine Uygulanması. Yüksek Lisans Tezi, Sosyal Bilimler Enstitüsü, Denizli.

[25] Şimşir, F., Demir, H. İ. and Azdemir, S., (2018). Demir çelik sektöründe hibrid DEMATEL ve TOPSIS-ELECTRE yöntemleri ile hata türleri ve etkileri analizi. Academic Platform Journal of Engineering and Science 6(3), 22-34.

[26]Sorrentino, P., (2016). Use of failure mode and effects analysis to improve emergency department handoff processes. Clinical Nurse Specialist, Jan-Feb; 30(1), 28-37.

[27]Southard, P. B., Kumar, S. and Southard, C. A., (2011). A modified DELPHI methodology to conduct a failure modes effects analysis: a patient-centric effort in a clinical medical laboratory. Quality Management in Health Care 20(2), 131151.

[28]Taşçıŏlu, İ., (2007). Lüleburgaz Devlet Hastanesi ve Lüleburgaz 82. Yıl Devlet Hastanelerinde İş ve Çalışma Ortamından Kaynaklanan Riskler ve Bu Riskleri Hemşirelerin Algıllama Düzeylerinin Saptanması. Yüksek Lisans Tezi, Sağlık Bilimleri Enstitüsü, Edirne.

[29]Toktaş, P. and Can, G. F., (2019). Stochastic KEMIRA-M approach with consistent weightings. International Journal of Information Technology \& Decision Making, 18(03),793831.

[30]Toktaş, P. and Can, G. F., (2018). Şantiyelerin iş sağllğı ve güvenliği açısından risk düzeylerine göre KEMIRA-M yöntemi ile siralanması. Ergonomi, 1(3), 123 - 136.

[31]Turhan, F., (2006). Baskent Üniversitesi Hastanesi Çalışanlarının Mesleksel Risk Faktörleri ve Davranışlarının Değerlendirilmesi. Yüksek Lisans Tezi, Sağlık Bilimleri Enstitüsü, Ankara.

[32]Yıldırım, B. F. and Önder, E., (2015). Operasyonel, Yönetsel ve Stratejik Problemlerin Çözümünde Çok Kriterli Karar Verme Yöntemleri. DORA Basım-Yayın Dağıtım Ltd. Şti., 338, Bursa.

[33]Zegerek, S., (2014). Acil Servislerde Bulanık DEMATEL ve Bulanık GIA Yöntemleri ile Çok Kriterli Risk Değerlendirmesi. Yüksek Lisans Tezi, Fen Bilimleri Enstitüsü, Erzurum. 